\title{
A TIGHTLY COUPLED HEADING AND POSITIONING SYSTEM FOR INDOOR NAVIGATION OF MOBILE ROBOTS
}

\author{
Hikmet Yücel1*, Rifat Edizkan², Ahmet Yazıcı ${ }^{3}$ \\ ${ }^{1}$ HY Teknik Müh. Yaz. Dan. San. Tic. Ltd. Şti., Eskişehir \\ ORCID No: http://orcid.org/0000-0001-7657-3567
}

${ }^{2}$ Eskişehir Osmangazi University, Department of Electrical and Electronics Engineering, Eskişehir, ORCID No: http://orcid.org/0000-0002-5125-5631

${ }^{3}$ Eskişehir Osmangazi University, Department of Computer Engineering, Eskişehir ORCID No : http://orcid.org/0000-0001-5589-2032

\begin{tabular}{l}
\hline Keywords \\
\hline Indoor positioning \\
Heading \\
Fusion \\
Adaptive Kalman filter \\
Tightlycoupled system
\end{tabular}
Abstract

This study shows the effectiveness of data fusion techniques to achieve robust heading and position information in localization systems. The proposed system that has tightly coupled structure calculates heading and position of the mobile robot using the absolute and relative positioning subsystems. The relative positioning subsystem obtains heading and position information by using the odometry information and kinematic model of the robot. Absolute positioning subsystem calculates position and rough heading information using ultrasonic signals. In this study, firstly the robust heading information is calculated by combining absolute and relative heading with conventional Kalman Filter. The correction on the relative position measurement has been made by using this robust heading information. Finally, in order to obtain better positional information, an adaptive Kalman filter is applied for fusing the absolute position and the corrected relative position. In the experimental study, the positional accuracy and precision of the system is obtained as $63 \mathrm{~mm}$ and 86\% (for positional error $<100 \mathrm{~mm}$ ) respectively in the test environment. The proposed system gives more reliable, continuous, and less noisy heading and position information and is suitable for many tasks in indoorenvironments.

\section{GEZGİN ROBOTLARIN İÇ ORTAMDA SEYRÜSEFERİ İÇİN SIKI BAĞLI BİR BAŞ AÇISI VE KONUMLANDIRMA SISTEMİ}

\begin{tabular}{l}
\hline Anahtar Kelimeler \\
\hline İç ortam konumlandırma \\
Baş açısı \\
Tümleștirme \\
Adaptif Kalman süzgeci \\
Sıkı bağlı sistem
\end{tabular}

Öz

Bu çalışma, veri tümleștirme tekniklerinin, konumlandırma sistemlerinde gürbüz baş açısı ve konum bilgisi elde etmede etkinliğini göstermektedir. Önerilen system, gezgin robotun mutlak ve bağıl konumlandırma alt sistemlerini kullanarak baş açısı ve konum hesaplayan sıkı bağlı bir yapıya sahiptir. Bağıl konumlandırma alt sistemi, robotun odometre bilgilerini ve kinematik modelini kullanarak baş açısı ve konum bilgilerini elde eder. Mutlak konumlandırma sistemi ise, ultrasonik sinyalleri kullanarak konum ve aba baş açısı bilgisi elde etmektedir. Bu çalışmada, ilk olarak mutlak ve bağıl baş açısı bilgileri, geleneksel Kalman Filtresi ile tümleştirilerek gürbüz baş açısı bilgisi hesaplanmıştır. Daha sonra, bu gürbüz baş açısı bilgisi kullanılarak, bağıl konum ölçümünde düzeltme yapılmıștır. Son olarak, daha iyi konum bilgisi için, mutlak konum ve düzeltilmiş bağıl konumu tümleştirmek için uyarlanabilir bir Kalman filtresi uygulanmıştır. Deneysel çalışmada, sistemin konumsal doğruluğu ve hassasiyeti, test ortamı için sırasıyla $63 \mathrm{~mm}$ ve\% 86 (konum hatası <100mm için) olarak elde edilmiştir. Önerilen sistem daha güvenilir, sürekli ve daha az gürültülü baş açısı ve konum bilgisi vermekte olup iç ortamlardaki birçok görev için uygundur.

\begin{tabular}{llll}
\hline Araştırma Makalesi & \multicolumn{3}{c}{ Research Article } \\
BaşvuruTarihi & $: 24.03 .2021$ & Submission Date & $: 24.03 .2021$ \\
Kabul Tarihi & $: 04.09 .2021$ & Accepted Date & $: 04.09 .2021$ \\
\hline
\end{tabular}

\footnotetext{
*Sorumlu yazar; e-posta : hikmet.yucel@hyteknik.com
}

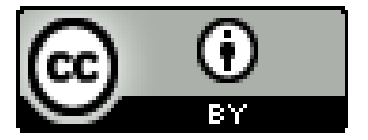

$\mathrm{Bu}$ eser, Creative Commons Attribution License (http://creativecommons.org/licenses/by/4.0/) hükümlerine göre açık erișimli bir makaledir.

This is an open access article under the terms of the Creative Commons Attribution License (http://creativecommons.org/licenses/by/4.0/). 


\section{Introduction}

In this study, a tightly coupled heading and positioning system is developed for the indoor navigation of mobile robots. The system consists of the absolute and relative positioning subsystems and each of which measures heading and position of the robot. Firstly, the heading is calculated by combining absolute and relative heading with conventional Kalman Filter. This heading is used to correct the relative position measurement. Finally, the robust position is obtained by combining the absolute position information and the corrected relative position information using AKF. The system is realized from the ICKON (Yayan, Yucel and Yazici, 2015) which is an absolute positioning system based on ultrasound and Pioneer 3-DX mobile robot whose positioning subsystem is used as relative positioning system.

The rest of this paper is organized as follows. In Section 2 , the ICKON system and the ultrasound-based position calculation method are introduced. New heading measurement method is also explained in this section. The details of the proposed tightly coupled system are given in Section 3. In Section 4, the test environment is described and experimental results are analysed. Section 5 gives the concluding remarks.

\section{Literature Review}

Many missions in autonomous mobile robot systems require performing some service tasks for indoor environments (Yazici, Sipahioglu and Parlaktuna, 2009). Accurate indoor position and heading are two important requirements in the mobile robot applications to complete the assigned task successfully (Kwon, Roh and Sung, 2006). Numerous systems have been developed for indoor positioning (Liu, Darabi, Banerjee and Liu, 2007; Farid, Nordin and Ismail, 2013; Khyam, Xinde, Ge and Pickering, 2017). The type of topology, signals, and measurements, and the position calculation method are some differences among the positioning systems. In Cricket (Priyantha, 2005), the transmitters are located at predetermined locations in the infrastructure, and there is a receiver on the mobile robot. The transmitters emit RF and ultrasonic signals at the same time. The receiver measures the distance using the time difference between the RF and ultrasonic signals and calculates the position. Ubisense (https://www.ubisense.net) is a commercial system that uses UWB (Ultra Wideband) signals. The transmitter is on the mobile robot, and the receivers are some fixed locations in the infrastructure. The infrastructure calculates the position of the mobile robot using the time difference between the receivers. Ekahau (https://www.ekahau.com) is a WiFi-based system. In this system, a fingerprint $\mathrm{RF}$ map is constructed for the indoor area, and then, the receiver on the mobile robot measures the signal strengths and estimates the position using the RF map. ICKON (Yayan et al., 2015) is a cellular and low-cost ultrasonic system. There are transmitters at fixed locations in the infrastructure. The transmitters emit pulses with predetermined delays. The mobile sensory unit (MSU) is on the mobile robot and measures the time difference in between the arriving signals. MSU calculates the position using the intersection of hyperbolas obtained from time difference measurements.

There are various systems that produce absolute and relative heading information. Magnetometers (compasses) are not reliable sensors indoors because man made infrastructure containing metal objects or electronic devices which are sources of magnetic interference cause deviation in Earth's magnetic field measurements (Zhang, Hoflinger and Reindl, 2012; Afzal, Renaudin and Lachapelle, 2011). Additionally, magnetometers often need calibration because of hard iron, soft iron and scale factor errors (Koo, Sung and Lee, 2009). Inertial devices, such as HRS (Heading Reference System), IMU (Inertial Measurement Unit) or INS (Inertial Navigation System) use gyroscopes in addition to magnetometers, but among other problems, gyros are prone to bias and it can produce large errors for long operation (Munguia and Grau, 2011). The drift level of the gyroscope is crucial because it cannot be reset during the measurement phase (Höflinger, Müller, Zhang, Reindl and Burgard, 2013). A gyroscope with long term bias stability, is very expensive (Munguia and Grau, 2011). In order to obtain accurate heading different methods are developed. Magnetometer output is processed with particle filter (Kwon et al., 2006). Munguia and Grau (2011) proposeda low cost and reliable Attitute Heading Reference System (AHRS) using Kalman Filter (KF) and Extended Kalman Filter (EKF). The KF was used to estimate the gyro bias. The EKF estimated kinematic sources. Similar to AHRS; Kang, Nam, Han and Lee (2012) proposed a system that improves heading estimation. The heading was obtained by fusing three embedded sensors' data (accelerometer, magnetometer and gyroscope) that are available in many smartphones. Heading was estimated using the rate of change of Received Signal Strength (RSS) in a WLAN system (Atia, Noureldin and Korenberg, 2012; Zhuang, Shen, Syed, Georgy, Syed and El-Sheimy, 2014).

In the literature, there are various systems that combine positions coming from different sources. The performance of the system that integrates INS and WiFi is improved by employing Adaptive Kalman Filter (AKF) and vehicle constraints (Chai, Chen, Edwan, Zhang and Loffeld, 2012). INS and WiFi RSS data are fused by Unscented Kalman Filter (UKF). AKF is used for adapting the measurement and process noise matrices in a Kalman filter. In another work, the positioning information calculated from WiFi fingerprinting is combined with inertial sensor measurement using Kalman Filters (Xiao, $\mathrm{Ni}$ and Toh, 2011). It is shown that 
the positioning accuracy is improved with the fingerprint-based localization and data fusion method. Wang, Low, He and Pham (2004) combined the output of the NAV200 indoor positioning system and the position obtained from the encoders with EKF. Sun, Kuo and Lin (2010) established wireless sensor network and signal strength was measured. These measurements were combined with accelerometer and orientation sensors measurements using UKF. Kim and Kim (2012) fused ultrasonic range measurements with odometry measurementsin indoor positioning systems using EKF. In that system, the transmitters emit both RF and ultrasonic signals at the same time. The time synchronisation is provided by sending the RF command from the robot to the infrastructure. EKF is used to improve the ultrasonic range measurements with knowledge of the position and heading of the robot.

For mobile robots, an encoder is an inexpensive choice for relative positioning. The position and the heading of the robot can be obtained using a kinematic model and encoders attached to the wheels. However, in relative positioning, the position is obtained using the heading, and the heading drifts quickly because of the cumulative error growth.

\section{Methods}

The authors declared that research and publication ethics were followed in this study.

\subsection{ICKON System}

The absolute positioning is obtained from the ultrasound-based system ICKON. The ICKON System is a fully ultrasonic system whose transmitters are located in the infrastructure, and the mobile sensory unit (MSU) is located on the mobile robot. The transmitters send signals with predetermined delays, and the MSU measures the time difference between the arrivals of the signals. The time difference of arrival (TDOA) measurements define hyperbolas, and the location is determined by solving for the intersection point. The structure of ICKON system, the calculation of absolute position and heading measurement method are given in this section.

\subsubsection{Structure of ICKON System}

The ICKON system consists of the central control unit (CentCU), the cell control unit (CCU), the communication system unit (CSU) and the mobile sensory unit (MSU). Each CCU controls a cell that covers a workspace of 20 $\mathrm{m}^{2}$.MSU is mounted on a mobile robot. Figure 1 shows the structure of the ICKON system.

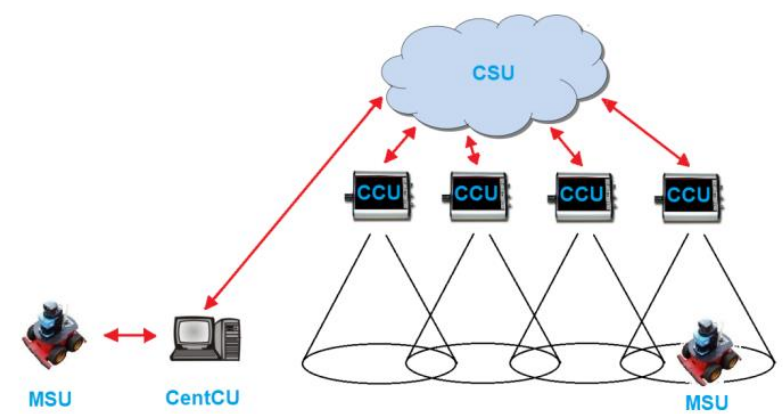

Figure 1. The ICKON system

The CentCU is a personal computer that runs the control software. The CentCU sends the ID numbers of the transmitters, the transmission times and other information to the CCU via the CSU. The CentCU is responsible for synchronisation among the CCUs. The CentCU also provides the modelling of the indoor environment and determination of the coverage area according to the transmitter placement. The CCUs control the transmitters located in the corresponding cells. It generates ASK (Amplitude Shift Keying) modulated signal for each transmitter. The carrier frequency is $40 \mathrm{KHz}$ and signal contains the transmitter ID. The CCU sends the signals to the transmitters in a predetermined cycle, as shown in Figure 2. The cycle start is triggered by the CentCU. Figure 2 shows the timing diagram for a cell with 4 transmitters.

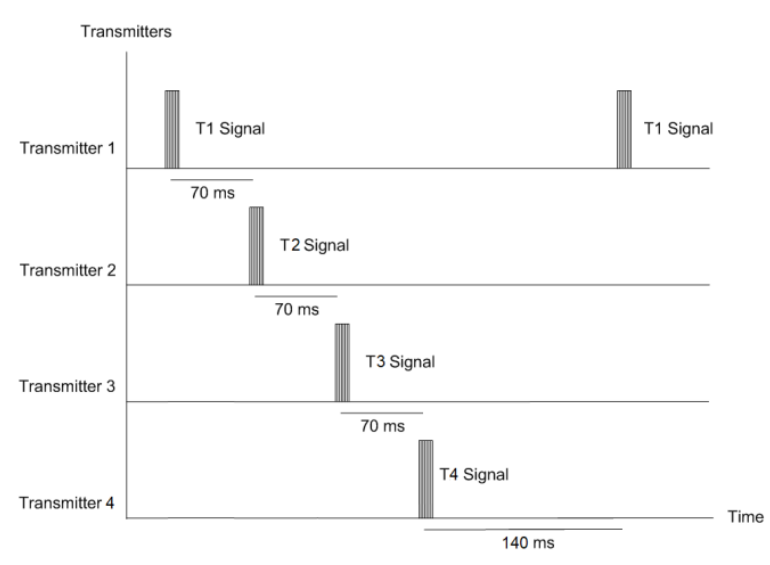

Figure2. Timing diagram forthe transmitters located in one cell.

MSU has six ultrasonic receivers to cover all directions, as shown in Figure 3. For every transmission, the MSU determines the receiver to which the signal was arrived first and then it decodes the transmitter ID and stores the time of arrival in microseconds. 


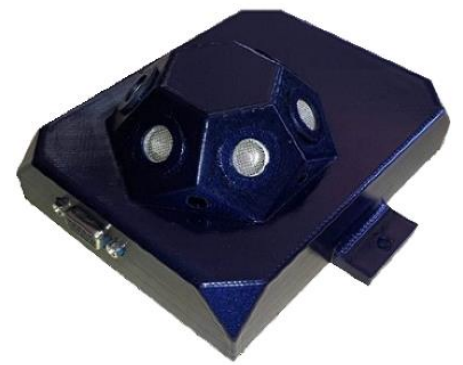

Figure 3. MSU of the ICKON system

The MSU finds the position of the transmitter from its ID from a preloaded lookup table. The TDOA measurements are used to define hyperbolas with known centres, which are the coordinates of the emitting transmitters. The positioning is performed by calculating the intersection of the hyperbolas. The CSU is implemented as an Ethernet-based network with a star topology. The CSU has a synchroniser unit that sends synchronisation signals to the CCU units. The synchronisation is activated by sending a specific command from the CentCU. The network may include switches, hubs, and routers.

\subsubsection{Position Calculation}

TDOA measurement can be performed between two transmitter signals and it defines a hyperbola. In the ICKON system, the MSU uses the hyperbola intersection method and the TDOA measurements for the position calculation. At least three signals are required to obtain two hyperbolas and calculate their intersection. The cone algorithm was developed to eliminate positioning errors due to reflections.

Assume that the first transmitter is the reference. Let $r_{i}$ denote the distance between the MSU transmitter $i$ whose coordinates are $\left(x_{i}, y_{i}, z_{i}\right)$. Let $r_{i 1}=r_{i}-r_{1}(i=$ $2,3, \ldots, M$ )where $M$ represents the number of transmitters in a cell. This difference can be calculated using the TDOA measurement and the speed of sound in the environment. The circle equations can be written as:

$$
\begin{gathered}
\left(x-x_{i}\right)+\left(y-y_{i}\right)+\left(z-z_{i}\right) \\
=\left(r_{1}+r_{i 1}\right)^{2}
\end{gathered}
$$

Subtracting the first equation from the other equations gives $M-1$ hyperbolic equations and they can be expressed as:

$$
2\left[\begin{array}{ccc}
x_{2}^{f} & y_{2}^{f} & z_{2}^{f} \\
x_{3}^{f} & y_{3}^{f} & z_{3}^{f} \\
\cdots & \cdots & \cdots \\
x_{i}^{f} & y_{i}^{f} & z_{i}^{f}
\end{array}\right]\left[\begin{array}{l}
x f \\
y^{f} \\
z^{f}
\end{array}\right]=\left[\begin{array}{c}
k_{2}^{f}-r_{21}^{2} \\
k_{3}^{f}-r_{31}^{2} \\
\cdots \\
k_{i}^{f}-r_{i 1}^{2}
\end{array}\right]+2 r_{1}\left[\begin{array}{c}
-r_{21} \\
-r_{31} \\
\cdots \\
-r_{i 1}
\end{array}\right]
$$

where

$$
\begin{aligned}
& x^{f}=x-x_{1}, \quad y^{f}=y-y_{1}, \quad z^{f}=z-z_{1} \\
& x_{i}^{f}=x_{i}-x_{1}, \quad(i=2,3, \ldots) \\
& k_{i}^{f}=\left(x_{i}^{f}\right)^{2}+\left(y_{i}^{f}\right)^{2}+\left(z_{i}^{f}\right)^{2}, \quad(i=2,3, \ldots)
\end{aligned}
$$

In the ICKON system, the least squares method is used to find the intersection point of the hyperbolas. The least squares solution can be written as in Equation (3)

$$
s=\frac{1}{2}\left(A^{T} A\right)^{-1} A^{T}\left(c+2 r_{1} d\right)
$$

where

$$
\begin{gathered}
A=\left[\begin{array}{lll}
x_{2}^{f} & y_{2}^{f} & z_{2}^{f} \\
x_{3}^{f} & y_{3}^{f} & z_{3}^{f} \\
\cdots & \cdots & \cdots \\
x_{i}^{f} & y_{i}^{f} & z_{i}^{f}
\end{array}\right] \quad s=\left[\begin{array}{c}
x^{f} \\
y^{f} \\
z^{f}
\end{array}\right] \\
c=\left[\begin{array}{c}
k_{2}^{f}-r_{21}^{2} \\
k_{3}^{f}-r_{31}^{2} \\
\cdots \\
k_{i}^{f}-r_{i 1}^{2}
\end{array}\right] \quad d=\left[\begin{array}{c}
-r_{21} \\
-r_{31} \\
\cdots \\
-r_{i 1}
\end{array}\right]
\end{gathered}
$$

The $s$ is a quadratic equation and its solution for $r_{1}$ gives the coordinates $x, y, z$ which is the coordinates of the MSU.

\subsubsection{Heading Calculation}

The ICKON System is an ultrasound based absolute positioning system and it has no capability to measure heading. In this study, a heading measurement method is developed and implemented with existing hardware. The MSU already has the information of the receiver ID that receives the signal first and the transmitter ID (which is coded on the transmission) for the calculation of its position. The heading calculation method is developed using the aforementioned information. This calculation is done with the first emitted signal in the cycle. Although it can be done with all the emitted 
signals, it is evaluated that to calculate heading once in each cycle is enough.

The angles used in heading calculation are shown in Figure 4.

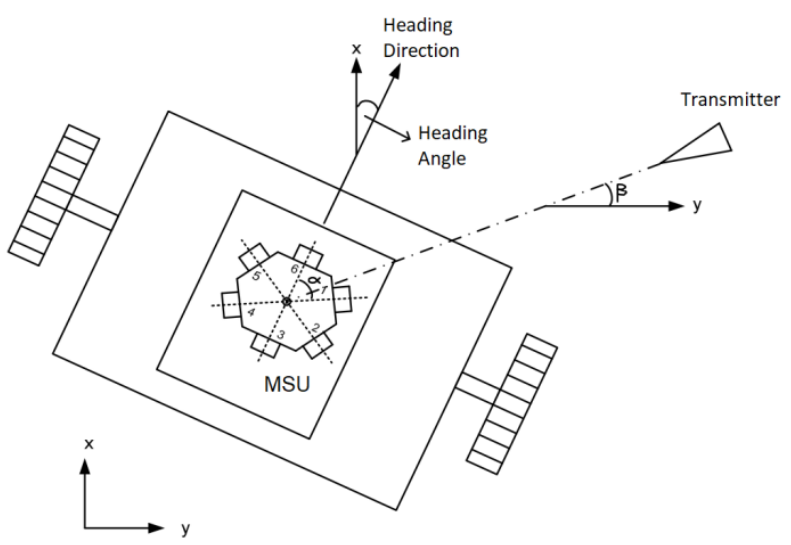

Figure 4. Angles used in heading calculation

The MSU can calculate its heading from the following equations

$$
\begin{aligned}
& \beta=\tan ^{-1}\left(\frac{x_{t}-x_{g}}{y_{t}-y_{g}}\right) \\
& \propto=i \cdot 60^{\circ} \\
& \gamma_{g}=90^{\circ}-(\alpha+\beta)
\end{aligned}
$$

where $\gamma_{\mathrm{g}}$ is the heading angle, $\mathrm{i}$ is the receiver ID, $\mathrm{x}_{\mathrm{t}}$ and $\mathrm{y}_{\mathrm{t}}$ denote the transmitter coordinates, $\mathrm{x}_{\mathrm{g}}$ and $\mathrm{y}_{\mathrm{g}}$ are the MSU coordinates.

This heading calculation is an absolute method. Although it does not contain cumulative error growth, it contains errors up to $30^{\circ}$ (since the angle between receivers is $60^{\circ}$ ), it is a noisy output and it gives the heading output when only it receives a signal. The ultrasound transmitters might be blocked by an obstacle. Also, a malfunction in the transmitters might occur. The heading of the MSU can be combined with the heading obtained from the relative positioning system using Kalman Filter. By the aid of relative positioning system, a continuous heading can be obtained. Besides, noise in the heading is decreased by using Kalman Filter.

\subsection{Proposed System}

The system has a tightly coupled structure because the relative position must be corrected before combining the positions, and this correction must be performed using reliable heading. Therefore, a combined heading is obtained using a conventional Kalman Filter first. This combined heading used to correct the relative positioning result, and finally, the corrected result of relative positioning is combined with the position result from ICKON using an Adaptive Kalman Filter. The proposed system also implements an absolute heading generation method as explained in Section 2.3. Although the accuracy of this heading information is low, it does not include cumulative drift with time. A block diagram of the proposed system is shown in Figure 5.

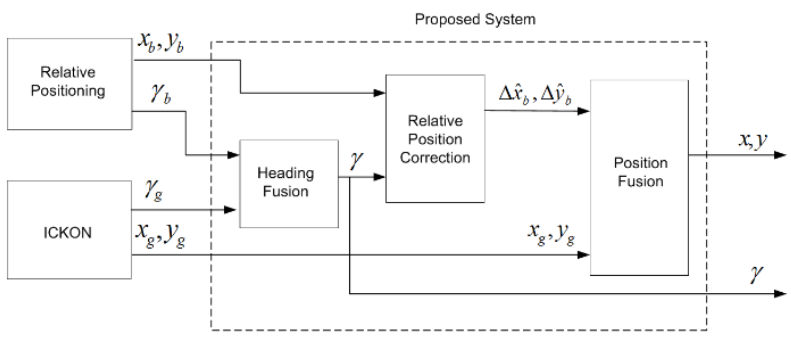

Figure 5. Block diagram of the proposed system

The proposed system has three main units: heading fusion, relative position correction and position fusion. The system takes the position and heading information from ICKON and the mobile robot.

The heading fusion unit combines the heading from the ICKON and the robot. The relative position correction unit corrects the position of the relative positioning system using the combined heading. The position fusion unit combines the MSU position information and the corrected position information from the relative positioning unit. The function of each unit is explained in the following sections.

\subsubsection{Heading Fusion Unit}

Almost all of the mobile robots have a relative positioning system based on encoders coupled to its main wheels. The relative positioning unit calculates the position and the heading of the robot using the kinematics of the robot and the encoder readings. The heading drifts quickly, and the position drifts because the heading is used in the position calculation.

The Kalman Filter is a very well-known tool for data fusion. It is frequently used to fuse relative and absolute measurements. A Kalman Filter is designed whose dynamics model and observation model are given in Equation (7-8) where $\gamma$ is the heading angle, $w$ is the process noise and $v$ is the measurement noise. The process noise standart deviation is taken as $2^{\circ}$ and to be on the safe side, the measurement noise standart deviation is exaggerated and taken to be $30^{\circ}$. 


$$
\begin{aligned}
& \gamma_{k+1}=\gamma_{k}+\Delta \gamma+w \\
& \gamma_{g}=\gamma_{k}+v
\end{aligned}
$$

The block diagram of the Heading Fusion Unit is given in Figure 6. The relative positioning unit of the mobile robot outputs $x_{b}, y_{b}$ and $\gamma_{b}$. The input of the Kalman Filter is $\Delta \gamma_{b}$ which is a backward difference of the heading obtained from the relative positioning system.

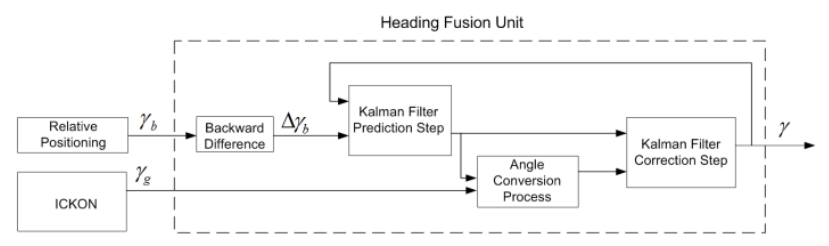

Figure 6. Heading fusion unit

The inputs of the Kalman Filter Correction Step are angles. Since angle is a cyclic value with modulus $360^{\circ}$, an angle conversion block re-represents the ICKON heading by adding or substracting $360^{\circ}$ to it according to the Kalman Filter Prediction Step output. This conversion is important for convergence of the Kalman Filter.

\subsubsection{Relative Position Correction Unit}

The relative positioning system of the mobile robot calculates the position using the heading. Because the heading drifts, the position also drifts. Combined heading is more reliable and does not drift. Therefore it can be used to calculate position instead of the heading of the relative positioning system.

The relative positioning gives $x_{b}$ and $y_{b}$ coordinates. $\Delta x_{b}$ and $\Delta y_{b}$ values are found from backward difference and the distance travelled in a $\operatorname{step}(\Delta d)$ is obtained from Equation(9).

$$
\Delta d=\sqrt{\left(\Delta x_{b}^{2}+\Delta y_{b}^{2}\right)}
$$

The $x_{b}, y_{b}, \Delta x_{b}$ and $\Delta y_{b}$ values depend on $\gamma_{g}$, so they drift with it. However, $\Delta d$ does not depend on $\gamma_{g}$, and the corrected values $\left(\Delta \hat{x}_{b}, \Delta \hat{y}_{b}\right)$ can be obtained using the combined heading angle $\gamma$, as in Equation (10-11).

$$
\Delta \hat{x}_{b}=\Delta d \cdot \operatorname{Cos}(\gamma)
$$

$$
\Delta \hat{y}_{b}=\Delta d \cdot \operatorname{Sin}(\gamma)
$$

A block diagram of the correction of the relative positioning is given in Figure 7 .

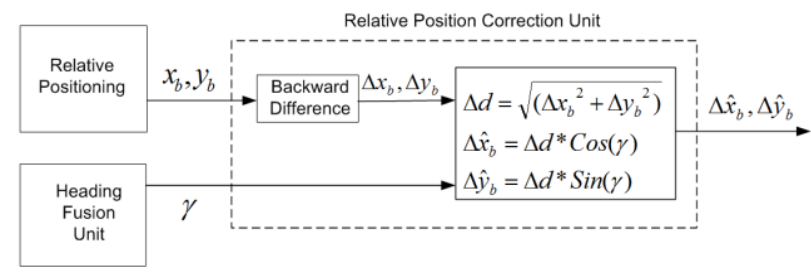

Figure 7. Relative position correction unit

\subsubsection{Position Fusion Unit}

After the correction of relative positioning result, a Kalman Filter can be applied to fuse the positions. A 2D Kalman Filter is used with following state model:

$$
\begin{aligned}
& x_{k+1}=x_{k}+\Delta \hat{x}_{b}+w_{x} \\
& y_{k+1}=y_{k}+\Delta \hat{y}_{b}+w_{y}
\end{aligned}
$$

The state vector, input vector, state transition and input control matrices are given below:

$$
s=\left[\begin{array}{l}
x \\
y
\end{array}\right], u=\left[\begin{array}{l}
\Delta \widehat{x}_{b} \\
\Delta \widehat{y}_{b}
\end{array}\right], A=B=\left[\begin{array}{ll}
1 & 0 \\
0 & 1
\end{array}\right]
$$

The process noise covariance is taken as in Equation (15) in millimetres due to the usage of the combined heading and simple model,

$$
Q=\left[\begin{array}{ll}
4 & 0 \\
0 & 4
\end{array}\right]
$$

The observation equations are given in Equation (1617)

$$
\begin{aligned}
& x_{g}=x+v_{x} \\
& y_{g}=y+v_{y}
\end{aligned}
$$

The observation vector and the observation model are expressed as:

$$
z=\left[\begin{array}{l}
x_{g} \\
y_{g}
\end{array}\right], H=\left[\begin{array}{ll}
1 & 0 \\
0 & 1
\end{array}\right]
$$


The observation noise covariance matrix defines the reliability of the calculated position. In some cases, reflections can affect the measurements, and the calculated position may include large errors. Because the Kalman Filter relies on the calculated position, as defined with the observation noise covariance, the Kalman Filter output jumps through the wrong result. An Adaptive Kalman Filter is used to overcome this problem. Instead of using a fixed observation noise covariance matrix, it is adapted according to the estimated error of the calculated position. There are two methods for error estimation: innovation-based and residual-based (Chai et al., 2012). The residual-based method is used in this study. The residual-based method states that the error can be estimated according to the difference between the MSU's and the Kalman Filter's output. Therefore, the observation noise covariance matrix is defined as in Equation (19). The coefficient $c_{\text {pos }}$ is determined empirically and it is set to 0.025 in our study.

$$
R_{\text {pos }}=c_{p o s} \cdot\left[\begin{array}{cc}
\left(x-x_{g}\right)^{2} & 0 \\
0 & \left(y-y_{g}\right)^{2}
\end{array}\right]
$$

\subsection{Tests}

The proposed system was tested in the environment shown in Figure 8. A Pioneer 3-DX mobile robot was used in the experiments. The test environment has narrow corridors, columns and stairs that makes the absolute positioning difficult because of the Line of Sight (LOS) blocking and reflection of ultrasound signal. Two different routes are tracked in the test environment, as shown in Figure 8. The locations of the transmitters are shown with black box. This was the same test setup used in study (Yayan et al., 2015). Four cells cover the test environment. There are sixty reference positions on the routes and the location of them are represented by red dot. Data were collected from these points by travelling each route for 10 tours.
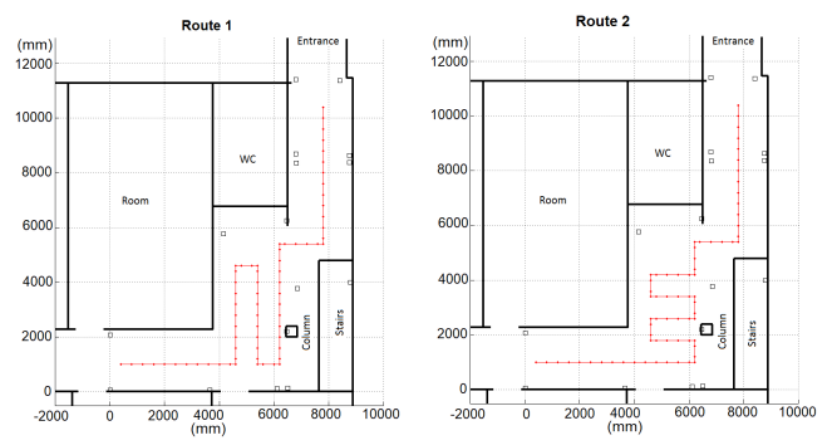

Figure 8. Route-1 and Route-2
In experiments, three types of data are collected by a computer placed on the mobile robot:

- The real position of the mobile robot to establish the reference

- The relative positioning results obtained from the related unit of the mobile robot

- The raw ultrasonic measurements obtained from the MSU

Time synchronisation is important between these data to justify the performance. The synchronisation can be done by using only one-time source and timestamp for all data collected. The system time of the computer is used as a time source at the millisecond level for all collected data.

To obtain the real position of the robot, the midpoint of the two main wheels is selected as a reference point. A laser pointer is placed to mark this reference point on the floor. A back view of the robot is shown in Figure 9.

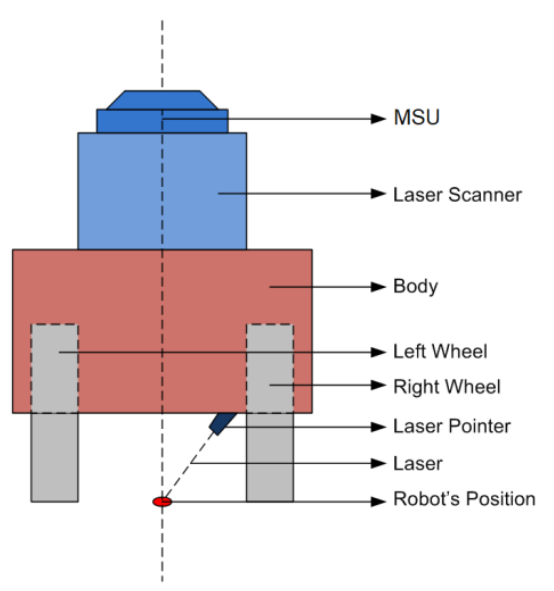

Figure 9. Back view of the robot.

The ceramic tiles on the floor of the test area are used as a grid. The coordinates of the ultrasonic transmitters are obtained by measuring the projections of the transmitters to the floor using a laser plumb and measuring their heights. A webcam is installed at the bottom of the mobile robot to record the laser pointer mark point and connected to the laptop computer via a USB connection. Rulers are drawn onto the crossings of tiles. A screenshot from the cam is shown in Figure 10. In this figure, the roller caster, laser pointer and the tile crossing can be easily observed. The time stamp of the computer is recorded on the video. 


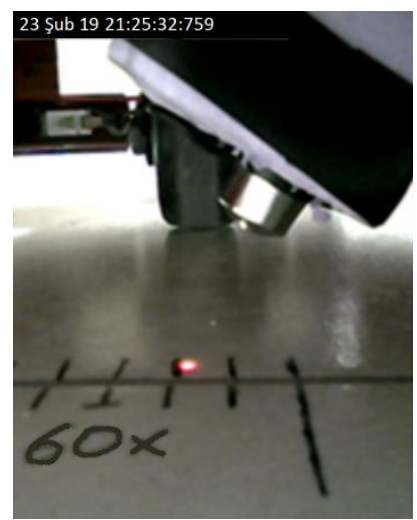

Figure 10. A screenshot from the webcam

The video is analysed and the real position, date and time are recorded manually for every tile crossing in the real position database. The accuracy of the real position is about $0.25 \mathrm{~cm}$ because the marks are $1 \mathrm{~cm}$ apart and diameter of the laser mark is less than $2 \mathrm{~mm}$. The relative positioning database is constructed from relative position, heading information, date and time.

The MSU is placed on the mobile robot such that the projection of the MSU aligns with the reference point for the real position, as shown in Figure 9. Ten tour experiments were conducted using 2 routes. The position error of the proposed system is calculated as the difference from the real position. The real positions are matched with the calculated positions by taking the time stamps of the real positions as a reference. Because the position refresh rate of the proposed system is a minimum of $10 \mathrm{~Hz}$, the matching error is, at most, $50 \mathrm{~ms}$ in time and $10 \mathrm{~mm}$ in distance.

\section{Results}

The position and error graphs for Route-1, Tour-7 and Route-2, Tour-3 are given as samples in Figure 11 and Figure 12 respectively. In the position graphs, the real positions are represented by a star, and the calculated positions are shown as lines with both axes in $\mathrm{mm}$. In the error graph, the $\mathrm{x}$-axis is the reference points and the $\mathrm{y}$ axis is the positioning error in $\mathrm{mm}$.
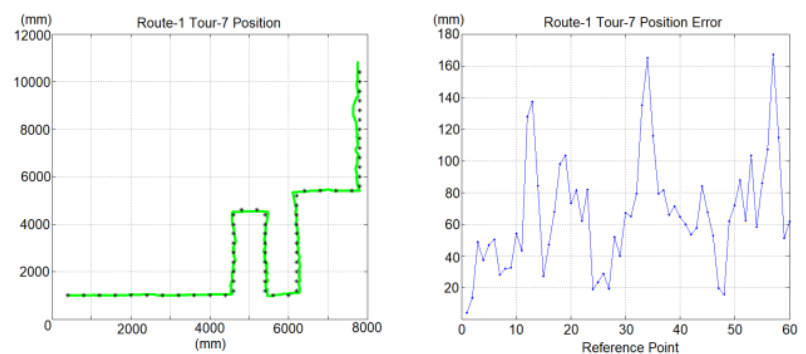

Figure 11. Calculated position and Error for Route-1, Tour-7
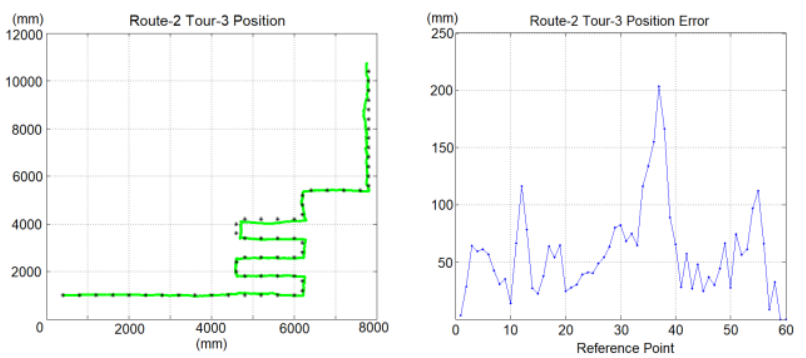

Figure 12. Calculated position and Error for Route-2, Tour-3

Since the encoder based relative positioning has error accumulation, naturally its output diverges from the route with time. Hence, it is not meaningful to make a comparison with the proposed system. Although MSU is for absolute positioning and it is not affected from error accumulation, it has relatively high noise and is not comparable with the proposed output considering the high level control.

In positioning applications, the basic parameters of the performance are the accuracy and precision. The accuracy can be expressed as the mean error, and the precision can be expressed as the standard deviation of the error. In practice, the precision can also be expressed as an error percentage below a certain value. In this study the values are selected as $30 \mathrm{~mm}, 60 \mathrm{~mm}$ and $100 \mathrm{~mm}$. Table 1 and Table 2 show the performance of the system for Route- 1 and Route- 2 , respectively.

Tablo 1

Performance of the system for Route-1

\begin{tabular}{|c|c|c|c|c|c|}
\hline $\begin{array}{l}\text { Tour } \\
\text { Num }\end{array}$ & $\begin{array}{l}\text { Mean } \\
\text { Error } \\
(\mathrm{mm})\end{array}$ & $\begin{array}{c}\text { Std } \\
\text { Dev } \\
(\mathrm{mm})\end{array}$ & $\begin{array}{c}\text { Err }< \\
30 \mathrm{~mm}\end{array}$ & $\begin{array}{c}\text { Err }< \\
60 \mathrm{~mm}\end{array}$ & $\begin{array}{c}\text { Err }< \\
100 \mathrm{~mm}\end{array}$ \\
\hline 1 & 77.65 & 66.02 & 11.6 & 41.6 & 81.6 \\
\hline 2 & 78.24 & 47.79 & 8.3 & 41.6 & 76.6 \\
\hline 3 & 67.74 & 26.57 & 5.0 & 50.0 & 86.6 \\
\hline 4 & 66.36 & 37.04 & 11.6 & 48.3 & 88.3 \\
\hline 5 & 153.17 & 169.03 & 10.0 & 26.6 & 56.6 \\
\hline 6 & 63.87 & 38.75 & 11.6 & 63.3 & 86.6 \\
\hline 7 & 66.59 & 35.71 & 16.6 & 45.0 & 83.3 \\
\hline 8 & 74.13 & 64.20 & 21.6 & 53.3 & 78.3 \\
\hline 9 & 69.17 & 47.09 & 18.3 & 50.0 & 80.0 \\
\hline 10 & 64.77 & 34.10 & 13.3 & 48.3 & 86.6 \\
\hline Mean & 77.87 & 56.63 & 12.8 & 46.8 & 80.5 \\
\hline
\end{tabular}


Tablo 2

Performance of the system for Route-2

\begin{tabular}{lccccc}
\hline $\begin{array}{l}\text { Tour } \\
\text { Num }\end{array}$ & $\begin{array}{c}\text { Mean } \\
\text { Error } \\
(\mathrm{mm})\end{array}$ & $\begin{array}{c}\text { Std } \\
\text { Dev } \\
(\mathrm{mm})\end{array}$ & $\begin{array}{c}\text { Err }< \\
30 \mathrm{~mm}\end{array}$ & $\begin{array}{c}\text { Err }< \\
60 \mathrm{~mm}\end{array}$ & $\begin{array}{c}\text { Err }< \\
100 \mathrm{~mm}\end{array}$ \\
\hline 1 & 60.61 & 35.64 & 15.0 & 58.3 & 88.3 \\
2 & 70.40 & 60.69 & 15.0 & 58.3 & 80.0 \\
3 & 58.15 & 39.49 & 25.0 & 56.6 & 88.3 \\
4 & 57.20 & 34.57 & 16.6 & 56.6 & 90.0 \\
5 & 61.66 & 30.54 & 13.3 & 51.6 & 91.6 \\
6 & 77.21 & 46.90 & 10.0 & 36.6 & 81.6 \\
7 & 56.47 & 33.29 & 15.0 & 70.0 & 86.6 \\
8 & 60.53 & 30.10 & 8.3 & 61.6 & 90.0 \\
9 & 58.49 & 35.00 & 13.3 & 65.0 & 90.0 \\
10 & 64.27 & 38.51 & 13.3 & 51.6 & 80.0 \\
Mean & 62.50 & 38.47 & 14.5 & 56.6 & 86.6 \\
\hline
\end{tabular}

The performance evaluation isdifferent than (Yayan et al., 2015) in which the time synchronisation was not used and performance was evaluated by cross track error. Cross track error is calculated as the shortest distance between the calculated position and the route. Therefore, the real position of the robot is not used in the error calculation. With that method, the average cross track error was calculated as $24 \mathrm{~mm}$. In our study, with the help of the time synchronisation, the real position of the robot at the position calculation time is recorded and the error is calculated as the distance between the calculated position and real position, not the closest point on the route.

The average accuracy of the proposed system is $78 \mathrm{~mm}$ for Route-1 and $63 \mathrm{~mm}$ for Route-2. The average precision of the system for less than $100 \mathrm{~mm}$ is $81 \%$ for Route- 1 and $86 \%$ for Route- 2 .

\section{Discussion}

The proposed system has ability to calculate reliable heading and position in indoor environments by implementing a tightly coupled structure. With this structure, heading and position from ICKON and Relative positioning system are fused with Kalman Filters and the accuracy and precision is increased. The system's accuracy is approximately $70 \mathrm{~mm}$ and its precision is $86 \%$ for less than $100 \mathrm{~mm}$. The results show that the proposed system is suitable for many tasks in indoor environments.

Proposed heading calculation is based on direction of reception of ultrasonic signals, therefore it is not affected by magnetic field deviations in indoors. Although ICKON heading and position outputs do not have cumulative drift, they are noisy results and they can be calculated only with the reception of the ultrasonic signals. Relative positioning outputs has low noise but they are highly affected by cumulative drift. Combination of ICKON and relative positioning by proposed system, resultant heading and position outputs has low noise, high accuracy and they are robust, continuous with high refresh rate even in the absence of ultrasonic signals. In addition to those; because the need for 3 different signals to calculate the position is no longer necessary, the installation cost in indoors containing stairs, columns, and corridors becomes less.

\section{Conclusion}

In this study, ICKON firmware is developed to calculate absolute heading and a novel system is proposed which uses ICKON and Relative positioning system outputs. Improving the positioning errors with the existing hardware in the ICKON system with a new iterative position calculation method will be our future work.

\section{Acknowledgements}

This work is supported by TUBITAK SME R\&D Support Program (Project Numbers. 7100932 and 7120742).

\section{Author Contributions}

This manuscript has been produced from Hikmet Yücel's thesis study. Rifat Edizkan and Ahmet Yazıcı were thesis advisor and co-advisor respectively. All the authors worked together in the preparation of the manuscript.

\section{Conflict of Interest}

There is no conflict of interest.

\section{References}

Afzal, M. H., Renaudin, V., \& Lachapelle, G. (2011). Magnetic field based heading estimation for pedestrian navigation environments. In 2011 International Conference on Indoor Positioning and Indoor Navigation (pp. 1-10). IEEE. doi: https://doi.org/10.1109/IPIN.2011.6071947

Atia, M. M., Noureldin, A., \& Korenberg, M. J. (2012). Dynamic propagation modeling for mobile users' position and heading estimation in wireless local area networks. IEEE Wireless Communications Letters, 1(2), 101-104. doi: https://doi.org/10.1109/WCL.2012.020612.11027 $\underline{9}$ 
Chai, W., Chen, C., Edwan, E., Zhang, J., \& Loffeld, 0. (2012). INS/Wi-Fi based indoor navigation using adaptive Kalman filtering and vehicle constraints. In 2012 9th Workshop on Positioning, Navigation and Communication (pp. 36-41). IEEE. doi: https://doi.org/10.1109/WPNC.2012.6268735

Farid, Z., Nordin, R., \& Ismail, M. (2013). Recent advances in wireless indoor localization techniques and system. Journal of Computer Networks and Communications, 2013.2 doi: https://doi.org/10.1155/2013/185138

Höflinger, F., Müller, J., Zhang, R., Reindl, L. M., \& Burgard, W. (2013). A wireless micro inertial measurement unit (IMU). IEEE Transactions on instrumentation and measurement, 62(9), 25832595. doi: https://doi.org/10.1109/ TIM.2013.2255977

Kang, W., Nam, S., Han, Y., \& Lee, S. (2012). Improved heading estimation for smartphone-based indoor positioning systems. In 2012 IEEE 23rd International Symposium on Personal, Indoor and Mobile Radio Communications-(PIMRC) (pp. 24492453). IEEE. doi: https://doi.org/10.1109/ PIMRC.2012.6362768

Khyam, M. O., Xinde, L., Ge, S. S., \& Pickering, M. R. (2017). Multiple access chirp-based ultrasonic positioning. IEEE Transactions on Instrumentation and Measurement, 66(12), 3126-3137. doi: https://doi.org/10.1109/TIM.2017.2737898

Kim, S. J., \& Kim, B. K. (2012). Dynamic ultrasonic hybrid localization system for indoor mobile robots. IEEE Transactions on Industrial Electronics, 60(10), 45624573. doi: https://doi.org/10.1109/ TIE.2012.2216235

Koo, W., Sung, S., \& Lee, Y. J. (2009). Development of realtime heading estimation algorithm using magnetometer/IMU. In 2009 ICCAS-SICE (pp. 42124216). IEEE. Retrieved from: https://ieeexplore.ieee.org/document/5332943

Kwon, W., Roh, K. S., \& Sung, H. K. (2006). Particle filterbased heading estimation using magnetic compasses for mobile robot navigation. In Proceedings 2006 IEEE International Conference on Robotics and Automation, 2006. ICRA 2006. (pp. 2705-2712). IEEE. doi: https://doi.org/10.1109/ $\underline{\text { ROBOT.2006.1642110 }}$

Liu, H., Darabi, H., Banerjee, P., \& Liu, J. (2007). Survey of wireless indoor positioning techniques and systems. IEEE Transactions on Systems, Man, and Cybernetics, Part C (Applications and Reviews), 37(6), 1067-1080. doi: https://doi.org/10.1109/TSMCC.2007.905750

Munguia, R. \& Grau, A. (2011). An attitude and heading reference system (AHRS) based in a dual filter. In
ETFA2011 (pp. 1-8). IEEE. doi: https://doi.org/0.1109/ETFA.2011.6059089

Priyantha, N. B. (2005). The cricket indoor location system (Doctoral dissertation, Massachusetts Institute of Technology). Retrieved from: https://dspace.mit.edu/handle/1721.1/33924

Sun, C. J., Kuo, H. Y., \& Lin, C. E. (2010). A sensor based indoor mobile localization and navigation using unscented Kalman filter. In IEEE/ION Position, Location and Navigation Symposium (pp. 327-331). IEEE. doi: https://doi.org/10.1109/ PLANS.2010.5507249

Wang, D., Low, C., He, B., \& Pham, M. (2004). Accurate positioning for real-time control purpose integration of GPS, NAV200 and encoder data. In ICARCV 2004 8th Control, Automation, Robotics and Vision Conference, 2004. (Vol. 1, pp. 161-166). IEEE. doi: https://doi.org/10.1109/ICARCV.2004.1468816

Xiao, W., Ni, W., \& Toh, Y. K. (2011). Integrated Wi-Fi fingerprinting and inertial sensing for indoor positioning. In 2011 International Conference on Indoor Positioning and Indoor Navigation (pp. 1-6). IEEE. doi: https://doi.org/10.1109/ IPIN.2011.6071921

Yayan, U., Yucel, H.\& Yazici, A. (2015). A low cost ultrasonic based positioning system for the indoor navigation of mobile robots. Journal of Intelligent \& Robotic Systems, 78(3), 541-552. doi: https://doi.org/10.1007/s10846-014-0060-7

Yazici, A., Sipahioglu, A., \& Parlaktuna, O. (2009). Heuristic-based dynamic route planning method for a homogeneous multi-robot team. Advanced Robotics, 23(3), 269-287. doi: https://doi.org/10.1163/156855308X397479

Zhang, R., Hoflinger, F., \& Reindl, L. (2012). Inertial sensor based indoor localization and monitoring system for emergency responders. IEEE Sensors Journal, 13(2), 838-848. doi: https://doi.org/10.1109/ISEN.2012.2227593

Zhuang, Y., Shen, Z., Syed, Z., Georgy, J., Syed, H., \& ElSheimy, N. (2014). Autonomous WLAN heading and position for smartphones. In Proceedings of IEEE/ION PLANS 2014 (pp. 1113-1121). Retrieved from: $\quad$ https://www.ion.org/publications/ abstract.cfm?articleID $=11732$ 